\title{
EXPLORING THE INFLUENCE OF CUBISM ART MOVEMENT ON FASHION
}

\author{
VAISHALI MENON $^{1} \&$ S. KAUVERY BAI ${ }^{2}$ \\ ${ }^{I}$ Research Scholar, Department of Textiles and Clothing, SMT VHD Central Institute of Home Science, Bangalore, Karnataka, India \\ ${ }^{2}$ Associate Professor and HOD, Department of Textiles and Clothing, SMT VHD Central Institute of Home Science, Bangalore,
}

Karnataka, India

ABSTRACT
All art forms influence and inspire each other. Fashion too does not exist in isolation. Fashion is one of the important
art forms which can be influenced and inspired by paintings, sculpture, architecture, music etc.
Cubism was an avant-garde modern art movement which had a huge impact on all art forms. Cubism was
characterized by simultaneous perspective, geometrical fractured forms, muted depthless colors etc. Later part of Cubism was
marked by the development of newer techniques like collage, photomontage and assemblage where textures was added to the
composition in the form of sand, letters and other found objects in bright colors.
The present study was undertaken to compare Cubism paintings with costumes of this era to evaluate the possibilities
of interrelationship between fashion and cubism. Garments of this era were analyzed for color, silhouettes, embellishments and
fabrics to find parallel influences with paintings during 1906 to 1930.
From the above study, it was found that Paintings during Cubism influenced silhouette, color, texture and
embellishments of the costumes worn in this era.
Synthetic cubism gave rise to newer techniques like bias cut, creating textures with pin tucks, beads, and lace with
KEYWORDS: Cubism, Art movement, Avant Garde, Monochrome, Geometric Silhouette, Deconstruction, Surface Texture \&
Simultaneous Perspective

Received: Dec 23, 2017; Accepted: Jan 13, 2018; Published: Feb 01, 2018; Paper Id.: IJTFTFEB20183

\section{INTRODUCTION}

Art is a symbolic expression of ideas, thoughts, and emotions. It has the power to move our souls, stimulate our senses and challenge us intellectually. Art is influenced by culture and in turn helps to change culture. All the art forms respond to the same stimuli and involves creativity as well as mastery of technique and materials.

Art movement is a distinctive method and form followed by various art forms which is linked to a historic period or set of ideas. Every art movement brings changes in the styles of different art forms like painting, sculpture, architecture, music etc., where there is a strong connection of thought process and creation which has similar building blocks of elements.

Cubism is one of the most important art movement which had a huge impact on all forms of arts in $20^{\text {th }}$ century. Cubists showed simultaneous perspective from multiple sides in geometrical forms, muted depthless colours and unspecified edges. This was a pioneering concept in the field of paintings. Many painters experienced freedom and shift 
of thought process in creating works of art during Cubism. They did not abide by the previous rules thereby paving a path for the development of newer techniques like Collage, Photomontage, Assemblage etc. which was adding sand, scrap material, cigar wrappers, labels, newspaper pieces, mixed media to the art work to create texture on the surface. Advances in technology also gave them newer synthetic pigments used in their brighter hues without fear. Forms were distorted and reassembled to give a unique abstract form to the painting.

Fashion does not exist in isolation. Fashion responds to external stimuli and changes according to changing aesthetics of anera. There are overlapping similarities between art world and fashion. We make associations and observe similar connections between different art forms to translate them into a new visual expression. Many designers have borrowed ideas from famous painters to design or embellish their creations, creating a new art form. Thus, the amalgamation of various art forms creates an exciting new product for contemporary use.

This study was undertaken to research and study Cubism as an art movement to find if it had any influence on prevailing fashion. Extensive research on costumes of this period was carried out to find parallel influences. These were further analyzed and substantiated by artists and fashion design students and faculties.

By exploring this parallel influence, we are trying to merge different art forms and educating masses about an avante garde movement in modern art.

\section{REVIEW OF LITERATURE}

Cubism is a $20^{\text {th }}$ century revolutionary style of modern art developed by Pablo Picasso and George Braque in response to a world that was witnessing more technological progress than in the previous centuries.

Cubism proposed fragmentation of forms, restricted themselves to earthy monochromes moving to more colorful and decorative styles and undertook many painterly experiments giving rise to new styles of Cubism. (www.metmuseum.org/toh/hd/cub)

Cubism has been divided into 3 phases: Early, Analytical and Synthetic Cubism.

Early Cubism (1904-1908): Picasso and Braque developed the sculptural sense of space in paintings in the beginning by applying elements of geometric forms to landscapes and human figures. Paul Cezanne and Henry Matisse influenced this period by Blue palette followed by a Rose period dominated by Pinks, Beiges, light Blue and Rose colour.

Analytical Cubism (1909-1914): Cubism became a fully developed style. The artist analyzed the subject from many different viewpoints and reconstructed it within a geometric framework. These images were unified using a subdued and limited palette of colours like Tan, Brown, Grays, Greens and Beige were used.

Synthetic Cubism (1914-1921):Braque started to complicate Analytical Cubism by adding texture and letters. Picasso was the first to use text and mixed media in his art work.

Artists developed different techniques of Collage, Photomontage, Assemblage etc. which involved adding paper, scrap material, labels, cigar wrappers, sand, cardboard, words etc.

There was wider use of colours, materials and contrasting textures.

Fashion is a direct influence of any changes that happen in the art world since it's a mirror of what society thinks and does within a certain period. 
There was a major shift from Victorian era and Renaissance fashion of extravagance and curved form to geometric and linear silhouettes of the first two decades of $20^{\text {th }}$ century.

From 1900 to 1908 the styles of gowns were more curvaceous with S shape silhouette, full and flare at the bottom, tight sleeves with ruffles on the edge.

1908 to 1914: S shape changed to straight line. Waistline moved up, skirts narrowed and grew shorter. The high boned collar was gradually replaced by low V necklines sometimes called as Pneumonia neckline. Costumes increasingly had oriental influence in the cut. Skirts were narrow at the hem called Hobble Skirts.

Paul Poiret designed geometric silhouettes like Lampshade Tunic, Minerate Tunic, Harem Skirt, Rectangular tailored suits etc.

Evening dresses used layers of sheer fabric with gold and silver embroidery, lace, beads and fringes placed over heavier fabrics.

1914 to 1918: During this time corsets were discarded and curved hourglass figure was replaced by the tube, drawers and cami knickers. One piece dresses were preferred. Skirts were shorter with easy fit bodice. Skirts use pleating, gathering or gores to achieve fullness.

1918-1920: Post world war 1 clothes were more comfortable and simpler since women started working in the offices, going by bicycles. Androgynous, boyish look was in fashion, giving the entire silhouette a linear, straight, geometric look, imitating the cubists painting styles.

Supply of fabric was limited due to war effect so silhouette became narrower. The Chemise dress (straight tube) designed by Jean Lanvin was popular. Newer fabrics became available like flannel, art silk or rayon, flamingo-silk and wool mixed crepe look, satin double faced etc. Nylon and other synthetics gained popularity coinciding with synthetic Cubism. New techniques in stitching were developed like bias cut, cording, pleating etc

\section{AIM}

Aim of this study is to explore the influence of Cubism art movement on Fashion

\section{OBJECTIVES}

- To explore and study Cubism art movement.

- To research Fashion silhouettes during Cubism.

- To analyze and co relate the influence of Cubism on Fashion.

- To evaluate the findings with the help of questionnairelopinionnaire from the artist and fashion design students and faculty.

\section{SCOPE}

The study was undertaken to find parallel influence of Cubism on fashion. This was done to find if the associations between different art forms after observing similar connections can be translated into a new visual expression. 


\section{METHODOLOGY}

\section{Phase 1: Collection of Data}

Data was collected from various books, internet, research papers, articles published in newspaper, e magazines and interviews with artists in the relevant field to achieve the first and second objective.

\section{Phase 2: Analysis of Data}

Collected data was analyzed in this phase to compare Cubism and Fashion to establish similar influences to achieve third objective.

Phase 3: Evaluation of Data

Evaluation of analyzed data was done with Painters and fashion designers to validate the findings with the help of Opinionnaire \Questionnaire. Results were discussed under different categories.

\section{PAINTINGS DURING CUBISM}
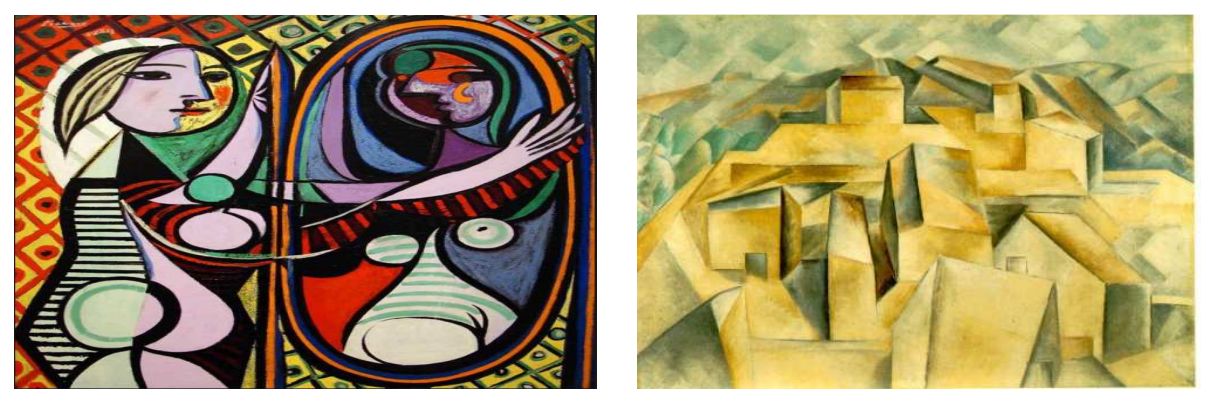

Figure 1: Blue Period Geometric Shapes Figure 2: Monochrome Simultaneous Perspective

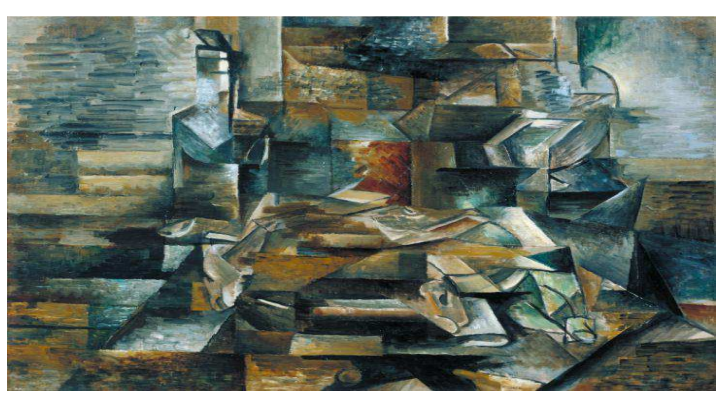

Figure 3: Collage, Geometric Shapes, Earth Colours

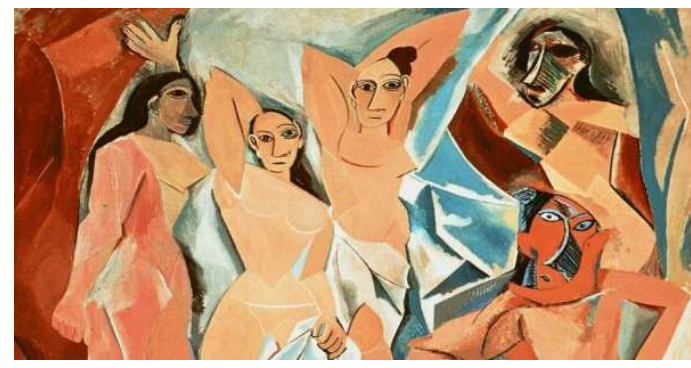

Figure 4: Beige, Rose Period. Curved Lines 


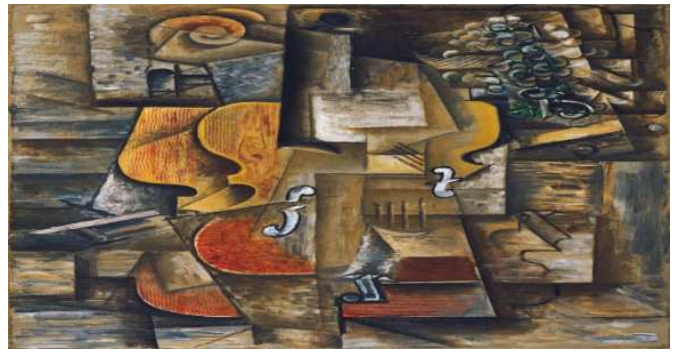

Figure 5: Curved Lines, Multicolours

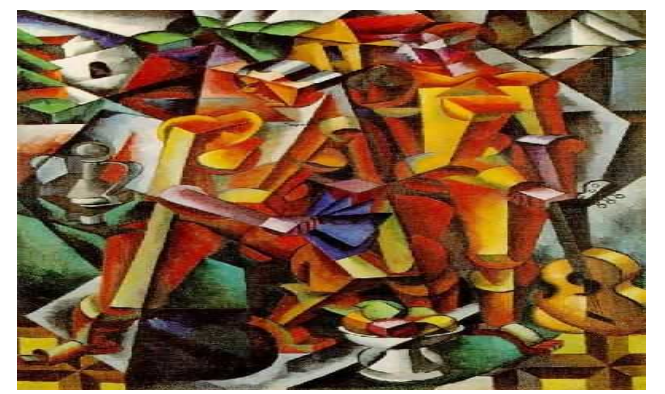

Figure 6: Assemblage/Collage

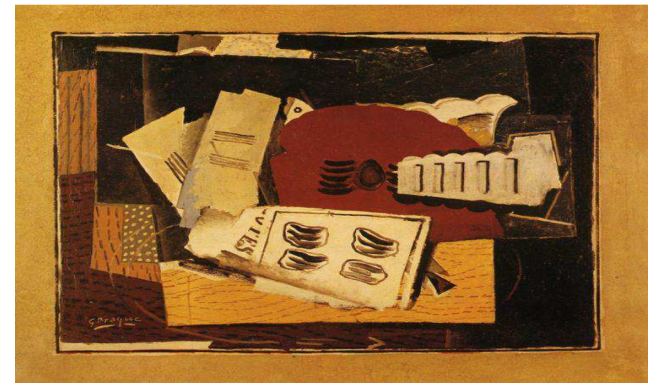

Figure 7: Bright Colours, Geometric Shapes

\section{COSTUMES DURING CUBISM}

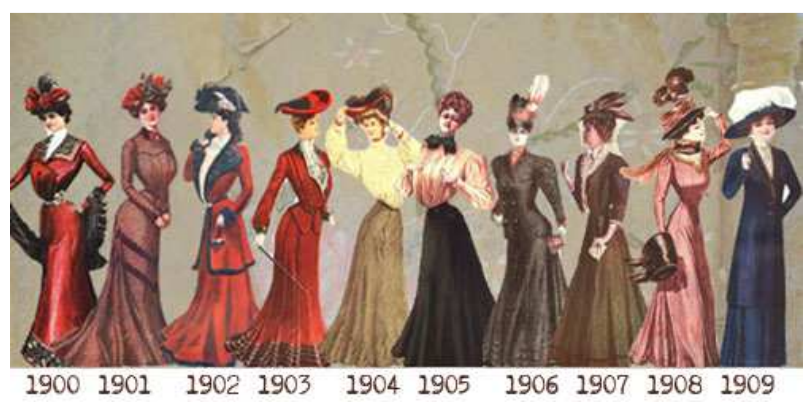

Figure 8

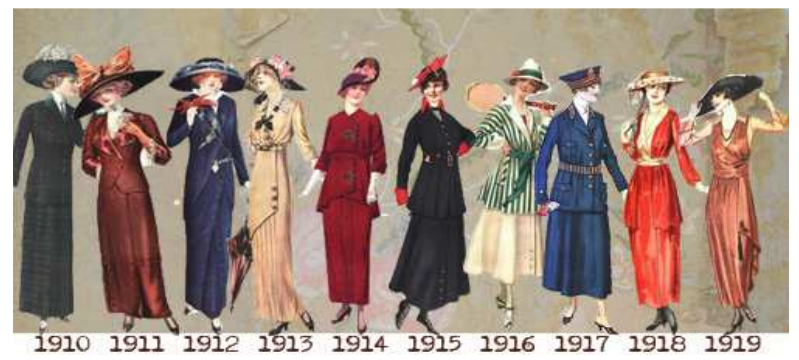

Figure 9 


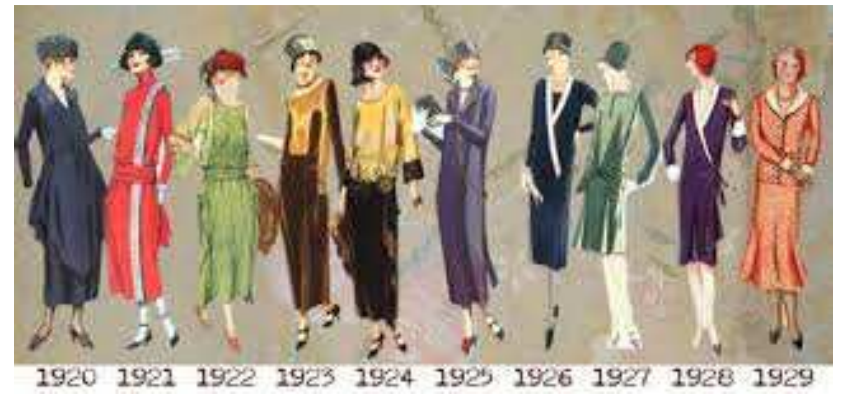

Figure 10

\section{RESULTS AND DISCUSSIONS}

The analysis of collected data through primary and secondary sources, along with results of evaluation study had given following conclusive results. These results are discussed under the broad headings of Silhouette, Colour, Texture, and Techniques used for Costumes during Cubism which are influenced by Paintings done during this modern art era.

\section{Silhouette}

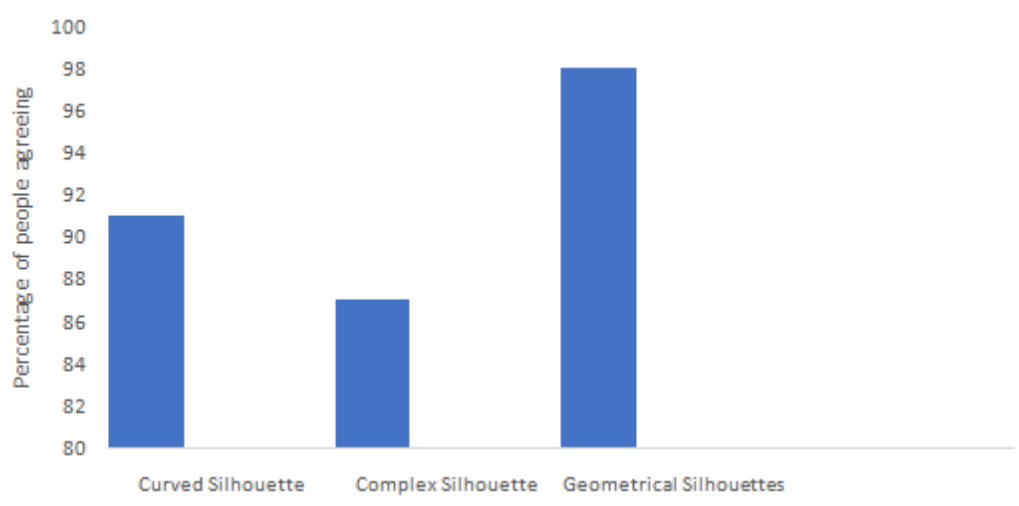

Figure 11: Effect of Cubism on Fashion Silhouette

From the above figure, it was found that

- $\quad 91 \%$ people agreed that Curved silhouette matched the curve lines of early Cubism.

- $\quad 87 \%$ people said Complex silhouette with layers of sheer fabric added for light effects can be influenced by simultaneous perspective drawn with complex compositions.

- $\quad 98 \%$ of people accepted that Geometrical silhouettes like Minaret Tunic, Lampshade Tunic, Rectangular skirt and square jackets were the direct result of Geometric forms which dominated paintings during Cubism.

- Thus $92 \%$ of people agreed that silhouette of costumes changed according to the changes in paintings.

- According to the result of the test of proportion: the value $4.1 * *>1.64>2.33$ (which is highly significant.) This calculated value lies in the critical region hence we reject the null hypothesis and accept the alternate hypothesis that the proportion of agree is more than the proportion of disagree. Thus, proving that the silhouette of costume changed according to changes in paintings during Cubism. 


\section{Colour}

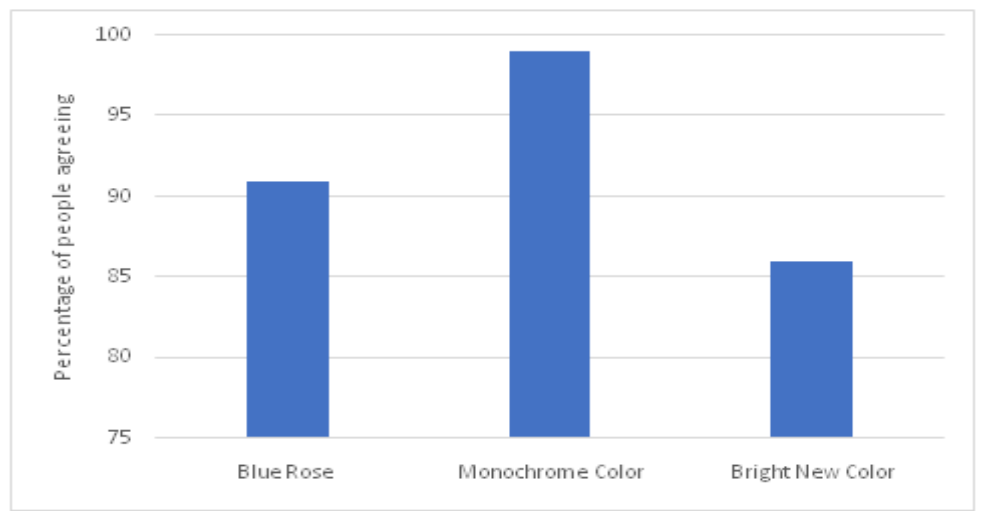

Figure 12: Effect of Cubism on Colour

From the above figure, it was found that

- $\quad 91 \%$ of people felt Blue, Pink and Beige colours dominated in garments coinciding with the Blue and Rose periods in paintings during Cubism movement.

- $\quad 99 \%$ of people said Monochromes dominated in fashion influenced by paintings during Cubism.

- $\quad 86 \%$ of people believed Bright new colours were used in costumes during synthetic Cubism influenced by Bright colours in paintings.

- Thus $92 \%$ people agreed that colours of costume were related to colours in paintings.

- According to the test of proportion: the resultant value $4.2 * *>1.64>2.33$ is highly significant. This value lies in the critical region so we reject the null hypothesis and accept the alternate hypothesis at $1 \%$ level of significance that the proportion of agree is more than the proportion of disagree. Thus, proving that colours in paintings influence the colours in costume and change according to changes in colour palette of paintings during different phases of Cubism.

\section{Texture}

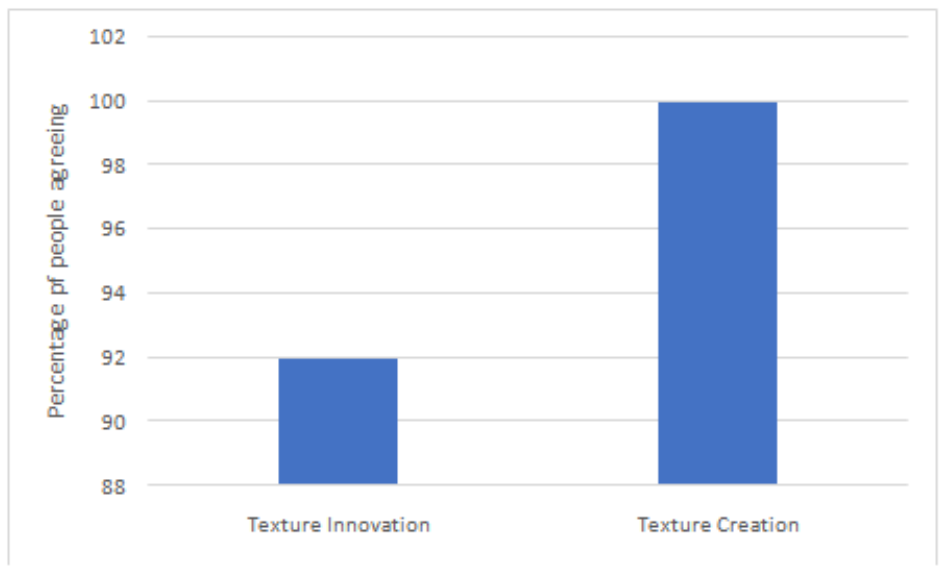

Figure 13: Effect of Cubism on Texture

From the above figure, it was found that

- $\quad 92 \%$ of people agreed that invention of new fabric like Rayon coincided with the innovation of new paints in art 
world.

- $100 \%$ of people agreed that texture was added to the surface of the fabric in the form of beads, lace, fabric and pin tucks resembling collage, Photomontage and Assemblage techniques of cubism paintings.

- Thus $96 \%$ of the people believed that new texture was invented and self-texture was created coinciding with innovation of new paints and self-texture with found objects in paintings.

- According to the results of the test of proportion the value $4.6^{* *}>1.64>2.33$ is highly significant lying in the critical region hence we reject the null hypothesis and accept the alternate hypothesis at $1 \%$ level of significance that the proportion of agree is more than proportion of disagree. Thus, proving that invention of new texture and innovation of self-texture coincided with similar innovations in paintings during Cubism art movement.

\section{Techniques}

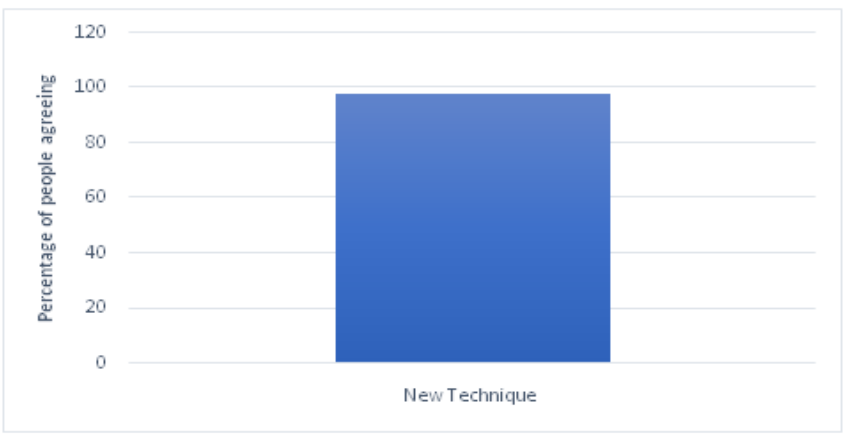

Figure 14: Effect of Cubism on Techniques

From the above figure, it was found that -

- $98 \%$ agreed that Bias cut, Applique, cording, Pleating, Tassels were the new techniques developed in garment construction coinciding with newer techniques in Paintings like Collage, Assemblage or Perspective drawing etc.

- According to the test of proportion: the resultant value $4.8^{* *}>1.64>2.33$ is highly significant which lies in the critical region so we reject the null hypothesis and accept the alternate hypothesis at $1 \%$ level of significance that proportion of agree is more than disagree. Thus, proving that new techniques in garment construction coincided with development of new techniques in paintings.

Table 1: Comparative Table of Parallel Influence between Cubism Fashion and Cubism Paintings

\begin{tabular}{|c|l|l|}
\hline $\begin{array}{c}\text { S. } \\
\text { No }\end{array}$ & \multicolumn{1}{|c|}{ Cubism Fashion } & \multicolumn{1}{c|}{ Cubism Paintings } \\
\hline 1 & Curved Silhouettes & Curved lines of early Cubism \\
\hline 2 & Geometrical silhouette & Geometrical forms in paintings \\
\hline 3 & Complex silhouette & Complex composition \\
\hline 4 & Monochromes in costume & Monochromes in earth tones of paintings \\
\hline 5 & Blue, pink, beige colours in costumes & Blue and Rose period in painting \\
\hline 6 & Bright new colours in costumes & Bright colours used in paintings \\
\hline 7 & Invention of new fabric like Rayon & Innovation of new paints \\
\hline 8 & $\begin{array}{l}\text { Creation of self-texture using beads, pin tucks, } \\
\text { lace or fabric. }\end{array}$ & $\begin{array}{l}\text { Creating texture using found object like sand, } \\
\text { labels, wood, letters or newspaper etc. }\end{array}$ \\
\hline 9 & $\begin{array}{l}\text { New techniques of garment construction and } \\
\text { embellishments like Bias cut, applique, cording, } \\
\text { pleating, Tassels etc. }\end{array}$ & $\begin{array}{l}\text { New techniques in paintings like Collage, } \\
\text { Assemblage, Perspective drawing, muted } \\
\text { depthless edges etc. }\end{array}$ \\
\hline
\end{tabular}


The analysis of collected data through primary and secondary sources, has given the following results.

Silhouttes: Outer shape of the garment changed according to changes in lines and shapes of Cubists paintings. As Cubists dismantled objects and reassembled them in paintings, fashion had a similar influence leading to deconstruction of a single garment into various components forming several layers in a single garment.

Curved silhouette of early cubism resembled curved lines of Cubist paintings.

Geometric forms in silhouettes like Lampshade tunics, Minerate tunic, narrow rectangular skirts with square jackets were all results of geometric forms dominating paintings during Cubism era.

Complex silhouette with layers of sheer fabric added for light and 3-dimensional effect resembled simultaneous perspective of 3 dimensional forms practiced during Cubism.

Colour: Colours in garments were influenced by dominant colour palette of paintings during this time.

Monochromes dominated fashion during 1908 to 1914. This trend in colours was influenced by evenly distributed earthy tones or monochromes with light and dark tones in paintings.

Prominent Blue, Pink and Beige colours in costumes were influenced by similar Blue and Rose periods in paintings during early Cubism.

Bright new colours costumes were seen during synthetic cubism, this was found to be similar in brighter shades of colours used in paintings and invention of new synthetic pigments.

Texture: Fabrics used for making garments changed during Cubism. Newer fabrics like Rayon, Nylon, mix of silk and wool etc were developed coinciding with the inventions in newer synthetic pigments. Textures were also added to the surface of the garment in the form of beads, pin tuck, laces, and different fabrics. This technique resembled the process of adding found objects, papers, letters etc on the surface of paintings.

Technique: Newer techniques were developed in garment construction which changed the way a garment was stitched. These techniques included Bias cut, Applique work, Cording, Fringing etc.

Several different techniques were also developed in paintings which revolutionized the painting world. These techniques were Collage, Assemblage, Simultaneous Perspective etc

\section{SUMMARY AND CONCLUSIONS}

Fashion is an expression of emotions like happiness, anger, melancholy. It can show different types of personalities like powerful, flirty, casual, artistic, serious etc through various outfits. Clothes are different experiences felt by the wearer and art is one of the important elements responsible for giving this experience. Paintings are considered as timeless art which are appreciated and popularized if you relate them to garments. Every art movement brings new changes which are perceived in all art forms.

This study was carried out to explore the influence of paintings during Cubism art movement on costumes of the same era. This was done to find if all art forms are interrelated or do they influence or inspire each other to create new visual expression giving birth to a new art form.

The researcher collected data on paintings during cubism, history of cubism art movement and costumes worn 
during this period from various books, magazines, research papers, e- magazines etc.

Key points of Cubism and key silhouettes worn during the same period were compared and analyzed to find similarities between these two art forms. This was further validated with the help of opinionnaire given to the experts in the field of art and fashion and results were tabulated in the form of graphs. Costumes were assessed for four parameters like colour, silhouettes, texture and techniques to find similarities with paintings. The researcher found a positive co-relation between paintings and garments. Silhouettes, colours, texture and embellishments and technique of garment construction were influenced by the parallel development in paintings.

These influences can be further incorporated in garments for contemporary wear using Indian fabrics like Khadi, creating innovative fashion which combines sensibilities of Avant garde modern art movement with heritage fabrics.

Thus, it can be concluded / that all art forms are interrelated. Fashion reflects current art movement which affects our thought process, acting as a mirror between two art forms.

\section{REFERENCES}

1. Anna C Krause, 1995, The story of Painting, Konnemen Publisher

2. Antlif M \& Leighton P (1957) Cubism and Culture, London, Thames and Hudson

3. Alice Mackerel, 2005, Art and Fashion, Bradford Ltd

4. Kifah Q. Saleh, M. R. Hashim, D. Bagnell \& P. Iamraksa, The Effect Study of Ge Concentration on FTIR Spectra and Surface Texture of 10-Period Multiple Quantum wells of Si0.4Ge0.6, Si0.8Ge0.2 with 5nm well Width, International Journal of Physics and Research (IJPR), Volume 3, Issue 4, September - October 2013, pp. 1-4

5. Alan Pipes,2008, Foundations of Art and Design, Laurence King Publishing

6. Charlotte Fiel, 2011,Fashion Sourcebook, Fiel Publishing Ltd

7. George Matter, 2014, The Psychology of Visual Arts-Eye, Brain and Art, Cambridge University Press

8. Robert Salso, 2013, Cognition and the Visual Arts, The MIT Press

9. Patrick De Rynck,2012, How to read a painting -Decoding and understanding old masters, Thames and Hudson

10. Martin Richard, 2013, Cubism and Fashion, Met Publication

11. Paulin Weston Thomas, 2014, Fashion History, Pepin Press

12. Met Gooding, 2005, Movements in Modern art-abstract art, Tate Publication

13. www.fashion-era.com/1914-1920-dress reform

14. www.metmuseum.org/toh/hd/cub

15. www.artyfactory.com/artappreciation/artmovements/cubism

16. www.slideshare.cubism 